\title{
The Pattern of Joints Involvement in Patients with Rheumatoid Arthritis in Rheumatology Clinic Dr. Hasan Sadikin General Hospital Bandung
}

\author{
Muhammad Kevin Pratama', Nur Atik², Laniyati Hamijoyo ${ }^{3}$
}

\begin{abstract}
${ }^{1}$ Faculty of
Medicine, University

of Padjajaran,

Bandung, Indonesia;

${ }^{2}$ Department of

Anatomy, Physiology,

and Cellular Biology,

Faculty of Medicine,

University of Padjajara,

Bandung, Indonesia;

${ }^{3}$ Department of

Internal Medicine,

Faculty of Medicine,

University of

Padjajaran / Dr. Hasan

Sadikin General

Hospital, Bandung,

Indonesia

Correspondence:

Muhammad Kevin

Pratama, MD

Bandung-Sumedang

KM.21, Jatinangor,

Sumedang

Email:prtmkvn@

gmail.com
\end{abstract}

\begin{abstract}
Background: Rheumatoid arthritis (RA) is a chronic inflammatory disease with primary manifestation in the joints. Early management of RA will prevent further joint damage. The joint damages, result of uncontrolled disease activity, will decrease patient's quality of life. RA should be diagnosed earlier and followed by early treatment initiation, in order to prevent further damages. This study aimed to determine the pattern of joint involvement in RA in order to made earlier diagnosis and treatment initiation.
\end{abstract}

Method: This research was conducted using descriptive study design. Data were obtained using interview of RA patients who coming to Rheumatology Clinic of Dr. Hasan Sadikin General Hospital from August 2016 to October 2016. Collected data included number of joints involvement, duration of therapy, and duration of illness after diagnosed according to the criteria of ACR / EULAR 2010.

Result: Ninety-seven RA patients were involved in this study. Subjects were dominantly women (87\%), the highest age group was $45-49$ years old (17.53\%), duration of the disease $<5$ years $(90.72 \%)$, and duration of therapy $>3$ months ( $86 \%)$. Joint that frequently involved at the time when the diagnosis made was first proximal interphalangeal (49.50\%), overall findings during the course of RA was the wrist joint (90.72\%). There were different tendency of joint involvement between the gender, knee joints occured in $53,84 \%$ male subjects, while PIP joints were accounted for $52,38 \%$ in female subjects.

Conclusion: The first PIP was the most common joint involved in RA patients when the diagnosis made. The wrist joint involvement was dominantly found in overall course of RA. Knee joint involvement was majorly found in male RA patients, whereas female RA patients would suffer mostly from PIP joint involvement.

Keywords: involvement pattern, joints, rheumatoid arthritis

\section{Introduction}

Rheumatoid arthritis (RA) is a chronic inflammatory condition of unknown etiology and characterized by symmetric peripheral polyarthritis. RA is the most common form of chronic inflammation involving the joints and often ended in joint damage and physical disability. ${ }^{1}$ It is one of the chronic inflammatory disease with the highest prevalence of $0.5-0.8 \%$ among adult population in the world. ${ }^{2}$ Although there has been evidence that overall RA incidence has been reduced over the past few decades, but its prevalence is not changed. ${ }^{3}$ According to the data from Indonesia Basic Health Research (Riskesdas) 2007 and from National Socioeconomic Survey (2007), the prevalence of RA in Indonesia was around $0.1 \% .{ }^{11}$

Diagnosis of RA is made based on the signs and symptoms of chronic inflammation, with the laboratorium and radiologic results. ${ }^{4}$ In 2010, a collaborative effort conducted between the American College of Rheumatology (ACR) and the European League Against Rheumatism (EULAR) revised the 1987 classification criteria for RA. ${ }^{5}$ It was done in attempt to make a faster diagnosis of RA so patients will get earlier treatment. ${ }^{6,7}$ Joint damages as the result of uncontrolled RA may decrease the patient's quality of life.

RA should be diagnosed as soon as possible, followed by early treatment initiation. Early detection of RA will provide a better disease management. Besides, it also could prevent many RA complications, of which the most frequent is joints damage. ${ }^{7}$ This study aimed to provide a better management of RA by determining the pattern of joint involvement in RA in order to made earlier diagnosis, so that further complication can be prevented.

\section{Methods}

The study was conducted from August to October 2016 at Dr. Hasan Sadikin General Hospital using a descriptive design study. The subjects were all patients who came to Rheumatology Clinic Dr. Hasan Sadikin General Hospital. The inclusion criteria was all patients who has been diagnosed as RA based on ACR / EULAR 2010 criteria. The exclusion criteria were patients with incomplete or 
missing data and the presence of other autoimmune rheumatic diseases or other joint problems. Minimum samples required in this study were 97 determined based on the categorical descriptive study formula to estimate the proportion of the population.

The data were taken by interviewing subjects, as the primary data, and collecting information from their medical records, as the secondary data. The data were analyzed descriptively by counting the number and the percentage of the joints involvement which has been examined by the Residents of Internal Medicine Department through the standardized examination. The variables in this study were gender, age, occupation, ethnic, duration of therapy, duration of illness, number of overall findings and manifestations when diagnosed as RA.

Data collection have been approved by the Ethic Committee on Health Research of Faculty of Medicine Universitas Padjadjaran and Ethics Committee on Health Research of Dr Hasan Sadikin General Hospital, Bandung. Data was processed using Microsoft Excel 2010 program.

\section{Result}

The number of samples obtained in this study was 97 . Most of them were women (87\%). Table 1 shows the characteristics of RA patients by their group age. The division of this age group is done to see if the prevalence of RA is not influenced by age, according to the previous study's results. ${ }^{3}$ Dominant age group diagnosed with RA is $45-49$ years $(17,53 \%)$.

Table 1. Age Group Characteristic in RA Patients

\begin{tabular}{cccc}
\hline Age & $\begin{array}{c}\text { Men } \\
(\mathbf{n}=\mathbf{1 3})\end{array}$ & $\begin{array}{c}\text { Women } \\
(\mathbf{n = 8 4})\end{array}$ & Total, N(\%) \\
\hline $15-19$ & 0 & 2 & $2(2.06 \%)$ \\
$20-24$ & 1 & 4 & $5(5.15 \%)$ \\
$25-29$ & 1 & 4 & $5(5.15 \%)$ \\
$30-34$ & 3 & 7 & $10(10.31 \%)$ \\
$35-39$ & 0 & 13 & $13(13.40 \%)$ \\
$40-44$ & 0 & 13 & $13(13.40 \%)$ \\
$45-49$ & 2 & 15 & $17(17.53 \%)$ \\
$50-54$ & 2 & 9 & $11(11.34 \%)$ \\
$55-59$ & 1 & 10 & $11(11.34 \%)$ \\
$60-54$ & 1 & 3 & $4(4.12 \%)$ \\
$65-69$ & 0 & 2 & $2(2.06 \%)$ \\
$70-74$ & 2 & 2 & $4(4.12 \%)$ \\
$\geq 75$ & 0 & 0 & 0 \\
\hline
\end{tabular}

According to the previous studies, RA is one of the autoimmune diseases which are strongly associated with gender, race, and ethnic origin as internal risk factors and environmental exposures as external risk factors. ${ }^{4}$ The distribution of patients based on characteristics gender, occupation and ethnic origin, are presented on Figure 1.
Figure 1. Occupation Characteristics of Male Subjects

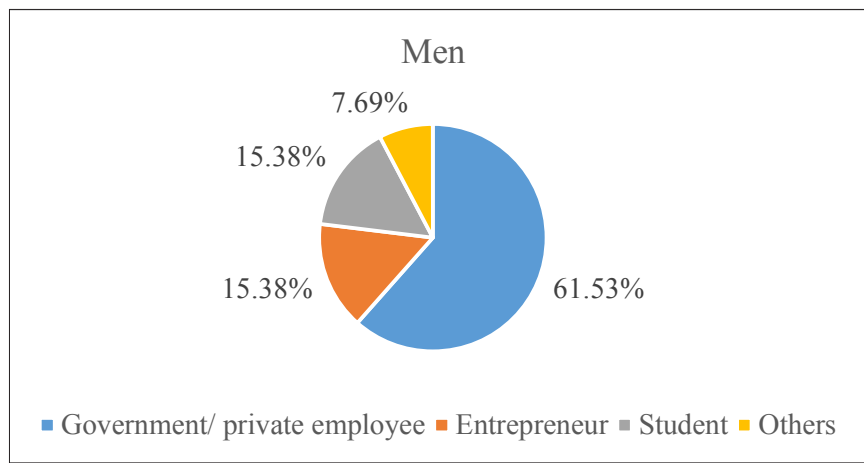

Figure 2. Occupation Characteristics of Female Subjects

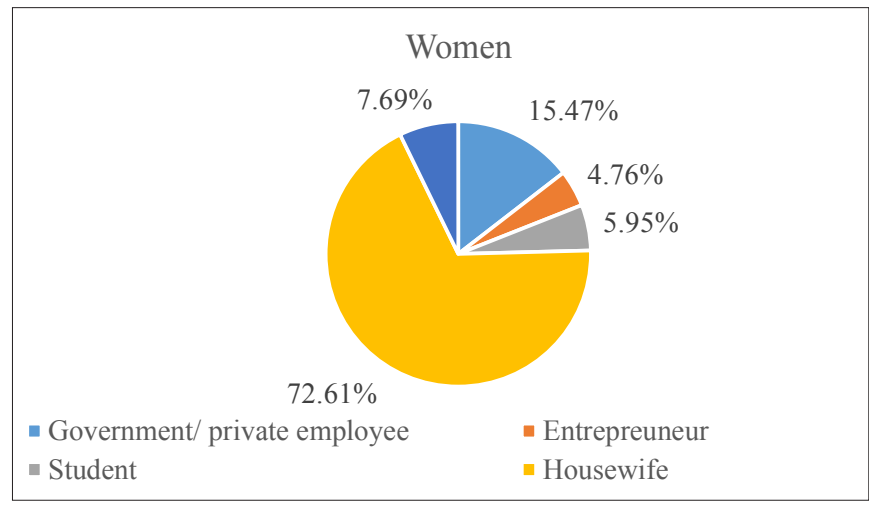

RA was found commonly in women $(84 ; 87 \%)$ than in men patients. Figure 2 shows female subjects in the study, mostly worked as a housewife (61 patients; 72.61\%), male subjects mostly worked as civil servants / private employees (8; $61.53 \%$ ), and all subjects are mostly Sundanese (82; 84.54\%).

Figures 3 and 4 show the pattern of joint involvement in patients with RA in Rheumatology clinic of Dr. Hasan Sadikin General Hospital based on joint involvement at the time of diagnosis and overall course of the disease. The highest percentage of joint involved when RA diagnosed in male patients was knee joint (53.84\%) and in female patients was proximal interphalangeal joint $(52.38 \%)$. The joint involvement found in overall course of RA in male subjects was the knees joint (84.61\%) and in female patients was the wrist joint $(91.67 \%)$. Without gender classification, the joint that showed the highest percentage at the time of diagnosis was the proximal interphalanges $(49.50 \%)$, and the findings during the whole course of RA is wrist joint (90.72\%).

Figure 3. Pattern of Joint Involvement at the Time of Diagnosis

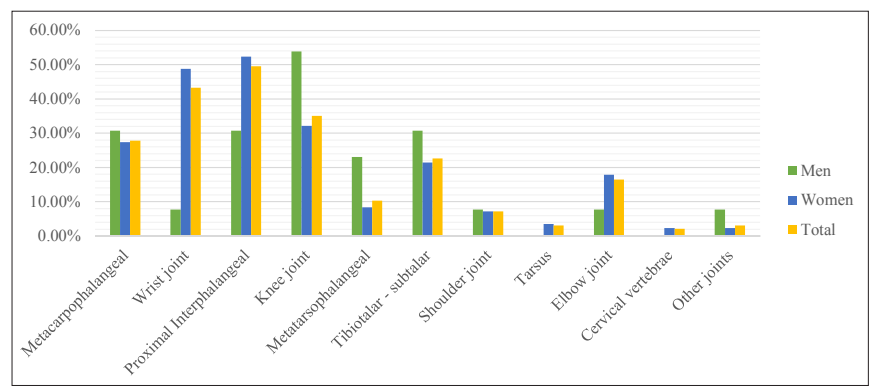


Figure 4. Pattern of Joint Involvement during Overall Course of RA

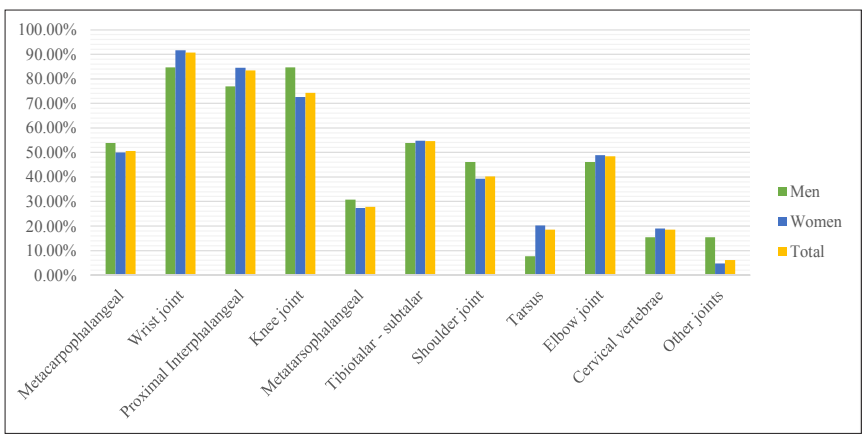

The results of the study conducted by Monti et al, suggested a correlation between the patient's response to therapy and duration of disease. ${ }^{6}$ In this study, there were differences in the number of joint manifestations of patients based on the duration of treatment and disease of each patient group. Most patient had received therapy for $>3$ months group (55.4\%); and had suffered from RA for $<5$ years group $(90.72 \%)$. Of the 88 patients who suffered from RA $<5$ years, 58 patients (65.91\%) had $\geq 5$ joints involvement, but also had lower percentage than patients suffered from RA for $>5$ years (77.78\%). Of 83 patients undergone therapy for $>3$ months, $53(63.86 \%)$ patients had $\geq 5$ joints involvement.

Table 2. Duration of Therapy and IIIness of The Subject

\begin{tabular}{ccccc}
\hline $\begin{array}{c}\text { Number } \\
\text { of joints } \\
\text { involvement }\end{array}$ & \multicolumn{2}{c}{$\begin{array}{c}\text { Duration of Therapy } \\
<\mathbf{3} \text { months }\end{array}$} & \multicolumn{3}{c}{$\begin{array}{c}\text { Duration of Illness } \\
\mathbf{3} \text { months }\end{array}$} & $<\mathbf{5}$ years & $>\mathbf{5}$ years \\
\hline 1 joint & $0(0 \%)$ & $0(0 \%)$ & $0(0 \%)$ & $0(0 \%)$ \\
$2-4$ joints & $6(42.86 \%)$ & $30(36.14 \%)$ & $30(34.09 \%)$ & $2(22.22 \%)$ \\
$\geq 5$ joints & $8(57.14 \%)$ & $53(63.86 \%)$ & $58(65.91 \%)$ & $7(77.78 \%)$ \\
Total & $14(14.43 \%)$ & $83(85.57 \%)$ & $88(90.72 \%)$ & $9(9.28 \%)$ \\
\hline
\end{tabular}

\section{Discussion}

This study showed that patients with RA were mostly women. These results are similar with the joint researches conducted by WHO in several countries included medium-to-low income countries group which showed the prevalence of female RA patients was five times higher than male patients. ${ }^{3}$ It suggested to be related with the important role of estrogen in activating inflammatory response within the pathogenesis of RA. ${ }^{12}$

Previous research showed the influence of gender on RA. ${ }^{3}$ Our results also supported that statement. We found the differences in the joint involvements of each gender. Unfortunately, there have not been any researches explained the role of gender on the difference joints manifestations. Moreover, there have not been any studies discussed the type of job that can be a risk factor for RA, so there is no explanation of the correlation between joint manifestations in RA with the type of occupations of each gender.

According to Iskandar A, et al., the most frequent joint appears in RA of both genders was metacarpofalangeal
$(85 \%){ }^{11}$ This is not consistent with the results of this study, based on the data obtained, regardless the gender of the patient, the joint that showed the highest percentage of occurrence for RA is wrist joint $(90.72 \%)$, while for the highest percentage occurrence at the time of diagnosis is the proximal interphalangeal joint (52.38\%).

More than 5 joints involvement were documented on patients with $>3$ months duration of therapy, this result was differed from the results of study conducted by Nell et al which showed a lower joint involvement after $>3$ month therapy.$^{10}$ Research conducted by Demourelle et al also found the maximum results of therapy were shown after the therapy at first 3 months of therapy and persisted throughout 3 years of followup. ${ }^{8}$ The difference results found in this study may be due to the differences of patient adherence to the treatment. Patients who tend to be less alert to the conditions at the onset of RA may have delay the diagnosis, therefore affect the progression of this disease, so patients will suffer the more severe condition, as described in Nagano et al. ${ }^{9}$

RA is a progressive disease if not treated immediately. ${ }^{12}$ Schneider, et al. mentioned that duration of illness affects the number of joints involved in the overall course of the disease. ${ }^{3}$ The finding was accordance with the our data that most patients who suffered $>5$ years had $\geq 5$ joints involvement.

We realized some limitations of this study. Our study cannot determine the correlation of cause and effects in the course of disease. The gender and occupation of RA patients might be related to their joints involvement, however further investigation with proper study design is needed to proved that.

\section{Conclusion}

The involvement of joints in patients with rheumatoid arthritis is different and depends on several aspects. Overall patients had PIP joint involvement at the time being diagnosed and wrist joint involvement in overall course of RA. Based on the gender, most male patients had knee joint involvement at the time being diagnosed as RA and at overall course of RA. While RA female patients mostly suffered PIP joint involvement at the time being diagnosed and wrist joint involvement at overall course of RA. Most patients have $\geq 5$ joints involvement even they had been treated for $>3$ months suggested the low compliance of patients. Further studies investigated the correlation of each study parameter is needed.

\section{References}

1. Aletaha D, Neogi T, Silman AJ, Funovits J, Felson DT, Bingham CO, et al. 2010 Rheumatoid Arthritis Classification Criteria. Arthritis Rheum. 2010;62(9):2569-81.

2. Kaneko Y, Takeuchi T. A Paradigm Shift in Rheumatoid Arthritis over the Past Decade. Intern Med. 2014;53:1895-903.

3. Papana A, Meng SJ, Wei YX, Wang W, Ruth M, Page C, et al. Prevalence of rheumatoid arthritis in low - and middle - income countries : A. J Glob Health. 2015;5(1):1-10. 
4. A. Gibofsky, MD, JD, FACP F. Overview of Epidemiology, Pathophysiology, and Diagnosis of Rheumatoid Arthritis. Am J Manag Care. 2010;18(13):295-302.

5. Kay J, Upchurch KS. ACR / EULAR 2010 rheumatoid arthritis classification criteria. Rheumatology. 2012;51:5-9.

6. Monti S, Montecucco C, Bugatti S, Caporali R. Rheumatoid arthritis treatment: the earlier the better to prevent joint damage. Rheum Musculoskelet Dis. 2015;1(1):1-5.

7. Heidari B. Rheumatoid Arthritis : Early diagnosis and treatment outcomes. Casp J Intern Med. 2011;2(1):161-70.

8. Demoruelle MK, Deane KD. Treatment Strategies in Early Rheumatoid Arthritis and Prevention of Rheumatoid Arthritis. Curr Rheumatol Rep. 2013;14(5):472-80.
9. Nagano J, Sudo N, Nagaoka S, Yukioka M, Kondo M. Life events, emotional responsiveness, and the functional prognosis of patients with rheumatoid arthritis. Biopsychosoc Med. 2015;9(15):1-7.

10. Nell VP, Machold KP, Eberl G, Stamm TA, Uffmann M, Smolen JS. Benefit of very early referral and very early therapy with disease-modifying antirheumatic drugs in patients with early rheumatoid arthritis. Rheumatology (Oxford). 2004; 43:906-14.

11. Iskandar A, Wachjudi RG. Diagnosis dan Prinsip Penatalaksanaan Artritis Reumatoid: Himpunan Makalah Lengkap Reumatologi Klinik Bandung. Bandung: Pusat Informasi IImiah, Departemen IImu Penyakit Dalam, Fakultas Kedokteran UNPAD, RS Dr Hasan Sadikin; 2014: p.309-40

12. Shah A, William E. Rheumatoid Arthritis. In: Kasper D, Fauci A, Hauser S, Longo D, Jameson J, Loscalzo J, editors. Harrison's principles of internal medicine. 19th ed. New York: McGraw - Hill Education; 2015, p2136-49 